\title{
BMJ Recruiting ethnic minority participants Open to a clinical trial: a qualitative study
}

\author{
Virginia MacNeill, ${ }^{1}$ Chinedu Nwokoro, ${ }^{1}$ Chris Griffiths, ${ }^{2}$ Jonathan Grigg, ${ }^{1}$ \\ Clive Seale ${ }^{2}$
}

To cite: MacNeill V, Nwokoro C, Griffiths C, et al. Recruiting ethnic minority participants to a clinical trial: a qualitative study. BMJ Open 2013:3:e002750.

doi:10.1136/bmjopen-2013002750

\section{- Prepublication history for this paper are available} online. To view these files please visit the journal online (http://dx.doi.org/10.1136/ bmjopen-2013-002750).

Received 18 February 2013 Revised 11 March 2013 Accepted 12 March 2013

This final article is available for use under the terms of the Creative Commons Attribution Non-Commercial 2.0 Licence; see http://bmjopen.bmj.com

${ }^{1}$ Centre for Paediatrics, Blizard Institute, Barts and the London School of Medicine and Dentistry, Queen Mary, University of London, London, UK ${ }^{2}$ Centre for Primary Care and Public Health, Blizard Institute, Barts and the London School of Medicine and Dentistry, Queen Mary, University of London, London, UK

Correspondence to Dr Chinedu Nwokoro; c.nwokoro@qmul.ac.uk

\section{ABSTRACT}

Objectives: To compare the motives and experiences of different ethnic groups participating in a randomised double blind placebo-controlled trial of montelukast in preschool wheeze, and to assess parents' or guardians' understanding of trial procedures and their implications, including the collection of genetic material.

Design: Qualitative interviews with parents or guardians. Setting: Interviews occurred in the homes of London children recruited to a national multicentre clinical trial following primary and secondary care attendance with wheeze.

Participants: 42 parents (20 of Bangladeshi origin, 10 white UK, 12 other ethnicities) of preschool children enrolled in a clinical trial.

Results: Bangladeshi families were relatively reluctant to participate in the qualitative study, despite strong engagement with the parent study. Anxiety related to wheezing was a common primary motive for trial enrolment. Parents viewed the trial as a route to improved treatment. Verbal delivery of trial information appeared more effective than study literature, especially for Bangladeshi families, with low parental literacy and high levels of trust in medical professionals potential contributors to this effect. All ethnic groups expressed a low understanding and/or retention of essential study concepts such as randomisation and genetic testing.

Conclusions: Bangladeshi families are particularly motivated to participate in clinical trials despite variable comprehension of study concepts. This motivation is more strongly contingent on strong researcher-subject rapport than on the quality of study literature. Trial teams seeking to recruit from South Asian populations should emphasise face-to-face verbal explanation of trial concepts and procedures and consider modified trial literature.

\section{INTRODUCTION \\ Background}

The under-representation of South Asians and other ethnic minority groups in clinical trials affects the generalisability of study findings and ultimately contributes to inequities in access to healthcare. ${ }^{12}$ Marked ethnic disparities exist in asthma outcomes ${ }^{3}$ and

\section{ARTICLE SUMMARY}

\section{Article focus}

- South Asians and ethnic minorities are underrepresented in clinical trials, affecting the applicability of results.

- South Asian group representatives suggest that a personal approach by researchers may improve recruitment.

- Parents enrolling young children in trials often have poor understanding of the implications of consent, whether this varies across ethnic groups is unknown.

\section{Key messages}

- Self-interest as well as altruism influence parental decision to enrol in a paediatric respiratory clinical trial.

- Decision to enrol is influenced more by trust in the research team than by written information.

- Careful verbal explanations of trial procedures, advantages and disadvantages are particularly important for parents of Bangladeshi origin.

Strengths and limitations of this study

- Data from a study population historically difficult to engage in quantitative or qualitative clinical research.

- The sample size is small, but adequate to achieve data saturation.

- There is an absence of data on parents declining to participate in the parent study.

ethnically delineated barriers to participation in trials concerning asthma interventions have been identified. These include a residual stigma attached to the asthmatic label, anxieties related to understanding the implications of participation, worries about the effects of trial medications, as well as cost and time concerns. ${ }^{4}$ Suggested solutions include provision of incentives, use of multilingual trial literature, employment of personal approaches and addressing researchers' reluctance to invite participation from the full cultural and linguistic spectrum. ${ }^{4-6}$

Currently, there is poor understanding of the perspective of ethnic minority parents involved in paediatric clinical trials. Previous work has 
explored the role of parents as responsible decision makers coreliant on the researchers and research governance procedures for guidance and protection. ${ }^{7}$ Significant elements include parents' poor comprehension of the trial process, ${ }^{8}$ the parental emotional turmoil related to paediatric illness and confusion born of the blurring of ethical boundaries between clinical and research practice..$^{9-11}$

\section{Parent study}

The current study is embedded within a randomised controlled trial (the parent study) of the genetic determinants of the efficacy of intermittent montelukast in preschool wheeze (PSW) and provides an opportunity to investigate the perspectives of the parents of trial participants. It was hypothesised that a genetically determined subgroup of patients (with higher urinary inflammatory mediators) would respond better to montelukast (have reduced unscheduled medical attendance) than their peers.

\section{Qualitative study}

PSW is a common, but poorly understood, disease of early childhood equally prevalent in UK children of South Asian and European origin. ${ }^{12}$ The ethnically diverse setting of the recruiting institution permits the principal aim of this study which was to compare attitudes and experiences of participating families across ethnic groups, including a significant number of participants of South Asian (Bangladeshi) origin. A secondary aim arises from the fact that both positive and negative public perceptions of pharmacogenetics exist. ${ }^{13}$ A recent focus group study involving diverse ethnic minority participants in biobank research found generally positive attitudes, with participation driven by perceptions of personal or collective benefit, despite limited understanding of genetics. ${ }^{14}{ }^{15}$ Hence, this work aims to describe ethnic variation in participants' understanding of the genetic element of the trial.

\section{METHODS}

\section{Parent study procedures}

Preschool children with a history of wheezing were recruited by a small team of children's research nurses and secondary care paediatricians following hospital attendance for wheeze or after receiving information from their primary care physician. For hospital attendees, recruitment occurred immediately prior to or shortly after discharge from hospital. Families received a trial information pack and subsequently discussed the study with the research team. Written and real-time verbal Bengali translation was available as required. Amenable parents then gave written informed consent (to paediatrician, research nurse or both) after which a mouth swab (for leukotriene-pathway genes) and urine sample (for leukotriene levels) were collected. Parents agreed to administer a 10-day course of oral medication (randomly allocated to montelukast or placebo) at the onset of a cold or wheezing symptoms, and to complete a daily diary record for the same period. They also received progress calls from the clinical research team at regular intervals and were encouraged to phone if they had any queries or concerns. Children were followed up for 1 year and the need for unscheduled respiratory medical attendance assessed. The qualitative study (QS) was based at the East London host centre of this multicentre trial and involved an audio-recorded semistructured interview with parents of enrolled children.

\section{Participant recruitment}

All participants in the trial and the qualitative substudy received written information about the study at recruitment. One hundred and thirty-nine parents gave formal written consent for their child to be enrolled in the trial and 85 of these parents gave written consent to a qualitative interview at the same time (table 2). The initial plan was to sample purposefully from the 85 consenting parents, aiming for maximum variation ${ }^{16}$ in terms of ethnicity, gender and other variables and then theoretically, according to iterative analysis of initial interviews.

\section{Data generation}

Individual interviews were considered the most appropriate method for data collection as this ensured confidentiality. A semistructured interview guide (box 1) for the interviews was developed following a literature review and discussions between VM and CS. ${ }^{4} 71718$ Interviews were conducted by VM, an experienced non-clinical qualitative researcher with an interest in the development of healthcare services in partnership with the patient population. Each interview took place in the parent's home and lasted 25-60 min. Preschool children were present in many instances. Interviews were conducted in English except one interview which required the assistance of a Bengali interpreter.

\section{Data analysis}

Interviews were audio-recorded and professionally transcribed verbatim. CS also reviewed a sample of interview transcripts during the course of the data collection period.

Table 1 Reasons given for decline or no response to request for qualitative interview

\begin{tabular}{ll}
\hline $\begin{array}{l}\text { Reasons given for decline or no } \\
\text { response to request for qualitative } \\
\text { interview }\end{array}$ & $\begin{array}{l}\text { Number } \\
\text { of } \\
\text { parents }\end{array}$ \\
\hline No response & 14 \\
Declined-no reason given & 11 \\
Declined-no time (employment related) & 4 \\
Declined-unable to speak English & 5 \\
Declined-no time (heavily pregnant or caring & 4 \\
for newborn) & \\
Declined-annual or religious or imminent & 5 \\
extended holiday & \\
Total number of parents & 43 \\
\hline
\end{tabular}


Table 2 Patterns of participation by ethnic group ${ }^{25}$

\begin{tabular}{|c|c|c|c|c|}
\hline & Bangladeshi & White British & Other* & Total \\
\hline $\begin{array}{l}\text { Percentage of local }<15 \text { population } \\
\text { by ethnic group } \dagger\end{array}$ & $22200(50 \%)$ & $14500(33 \%)$ & 7500 (17\%) & $44200(100 \%)$ \\
\hline $\begin{array}{l}\text { Parents with children enrolled in parent } \\
\text { study at time of QS }\end{array}$ & $94(68 \%)$ & $24(17 \%)$ & $21(15 \%)$ & $139(100 \%)$ \\
\hline $\begin{array}{l}\text { Parents consenting to QS at time of } \\
\text { enrolment to parent study ( } \% \text { of parents } \\
\text { enrolled, } 95 \% \mathrm{Cl} \text { ) }\end{array}$ & $48(51 \%, 41-61)$ & $17(71 \%, 51-85)$ & $20(95 \%, 76-100)$ & 85 \\
\hline $\begin{array}{l}\text { Qualitative interview completed (\% of } \\
\text { parents enrolled, } 95 \% \mathrm{Cl} \text { ) }\end{array}$ & $20(21 \%, 14-31)$ & $10(42 \%, 24-61)$ & $12(57 \%, 37-76)$ & 42 \\
\hline \multicolumn{5}{|c|}{$\begin{array}{l}\text { *Other interviewed parents: Africa }(n=6) \text {, Caribbean }(n=2) \text {, South America }(n=1) \text {, Middle East }(n=1) \text {, China }(n=1) \text {. } \\
\text { †There is no information available regarding ethnicity of the local under- } 5 \text { population. Data regarding under-15 children are deemed an } \\
\text { appropriate surrogate given that the overwhelming majority of local preschoolers survive to their teens and there is no evidence of an ethnically } \\
\text { divergent change in local birth rates in recent years. } \\
\text { QS, qualitative study. }\end{array}$} \\
\hline
\end{tabular}

Transcripts and field notes were imported into NVivo9, a qualitative data analysis programme. ${ }^{19} \mathrm{VM}$ and CS developed a coding framework that drew on the research questions, previous research about patient experiences of taking part in clinical trials and themes that emerged in the course of the analysis. The data were systematically coded and analysed using a modified grounded theory approach $^{20}$ incorporating the constant comparison technique to elicit key themes and explore deviant cases. ${ }^{21} 22$

\section{Ethics}

The study was reviewed and granted approval by the South East Research Ethics Committee (09/H1102/ 110). Written informed consent for QS was included as part of the parent study consent process and reconfirmed immediately before the qualitative interviews took place. The QS adhered to the RATS qualitative research review guidelines. $^{23}$

\section{RESULTS}

Of the 85 parents who gave written consent to structured interview at parent study enrolment, only half subsequently participated in a face-to-face interview. The reasons for non-participation are as stated in table 1. The remaining 42 parents agreed to a face-to-face

\section{Box 1 Topics included in the semistructured interview guide}

1. Family and child background information

- Child's history of wheeze

- Treatment and diagnosis

- Impact on child/parents/family

2. Parents experiences of joining the trial

- Motivations

- Consent and research governance processes

- Attitudes towards the collection of DNA and genetically guided therapy

3. Parents attitudes to and experiences of giving the trial drug to their child. interview, which took place over a 7-month period. There is no ideal sample size for qualitative studies $^{24}$ and this was a sufficient number of interviews within this opportunist sample to achieve data saturation.

At QS commencement, 139 families had consented to study enrolment; Bangladeshi participants were relatively over-represented in the parent study and white British under-represented. Bangladeshi parents taking part in the parent study were less likely than parents of 'other' ethnicity to be interviewed for the study reported here. Table 2 shows ethnically delineated differences in study participation.

We proceed to outline the characteristics of participants and then report on the themes that emerged from the interviews. These include

1. The reasons the parents gave for enrolling their child in the trial.

2. Participating parents' experience of the consent process and understanding of written and verbal information provided at the outset of the trial, in particular their understanding of the randomisation process.

3. Participating parents' understanding and response to the collection of genetic information.

4. The nature of participating parents' consultations with other people before deciding to take part.

Throughout, we report on differences and similarities between Bangladeshi and other participants.

\section{Characteristics of participants}

The majority of respondents were women. Bangladeshi participants had poorer spoken English than other groups and were less inclined to disclose their level of schooling, perhaps indicating sensitivity regarding poor educational attainment. Most households reported at least one working parent, but the numbers engaged in full time, part time or shift work were unclear due to guarded responses.

Parents of children in all groups reported anxiety related to their helplessness during wheezing attacks, 
often driven by the first hospital presentation. Major fears were of the potential for death or major long-term disability. These concerns drove a preoccupation with monitoring their child's health, together with anxiety about the potential progression of a cold to a wheeze with the attendant hospital visit, investigations and treatment. These fears were important drivers for trial participation, with hopes that participation might contribute to improved treatment for wheeze. Box 2 shows interview extracts relevant to this theme.

This was the emotional context within which parents were approached by the clinical trial team and asked if they would consider enrolling their child into the parent study. Parents reported being approached while inpatients or during follow-up appointments in primary or secondary care. Most children were already on prescribed medication for wheeze.

Half of the parents (11/20 Bangladeshi, 6/10 UK, 4/12 other) said that their primary reason for enrolling their child was that they hoped it would benefit their child in curtailing or curing the wheeze. A subset of these believed that the trial medicine represented an individual treatment regime for their child, perhaps conflating research with personal treatment. Others also viewed it as a route to additional information, treatments and medical attention by skilled physicians (box 3 ).

A third (15/42, of which 5/20 Bangladeshi, 4/10 UK, $6 / 12$ other) said that their aim was to help other children by contributing to the advancement of medical knowledge (although benefit to others was secondary to a consideration of potential benefit to their own child). Only four parents (2/10 UK, 2/12 other) voiced a

\section{Box 2 Anxieties about wheeze in children}

When I am putting him in the shower he was difficult to breath, he goes (makes gasping sound) with his hand in his mouth and I was scared and then I had to call an ambulance... he stayed in hospital for 2 days.(24F-Brazilian)

He wasn't too good they said we have to keep him in and he had oxygen up his nose. It was horrible. So he was in hospital for 3 days. That was the worst 3 days of my life. (41F-UK)

I'm so worried. My God. I know asthma may kill so I'm very worried (01F-Bangladeshi)

'My worst fear was that if l'm not with him or something like that....not breathe or...I don't know, I don't know much about asthma. I don't want him to get that. (08F-Egyptian)

'I can remember saying to (husband) very clearly if he dies don't come and collect me because I don't want to leave without him' (19F-Caribbean)

'I really didn't know how bad it was and how it can affect a child. And I really didn't know it was going to be the start of this long process of hospital after hospital after hospital.' (09F-UK)

'I am looking for a final treatment for her because this disease is not good for her health you know so I am looking for much better treatment for her and to find a treatment which is better for her whole life.' (33FM-Bangladeshi).

\section{Box 3 Other reasons for taking part}

\section{Benefit to child}

I wanted to see if it helps my daughter, to see if it got rid of her wheeze. (42F-Bangladeshi)

They said if you do this study your daughter is going to get better. (25F-Bangladeshi)

It's an extra medicine for my daughter that will help her, and it helps her stay at home rather than going to the GP or hospital all the time. (42F-Bangladeshi)

A very good way of you know, getting him seen by good doctors ... and hopefully getting answers you're looking for' (05F-UK)

\section{Benefit to others}

[My child] won't really benefit but from it ...this is obviously a trial so that they can try and prescribe this medicine in the future for children. (29F-UK)

It's good for the future. All children. Not for her [child] because she has already got it now, but yes, all children of the world. (40F-African)

Hopefully it's good for other children and good for her. (6M-Chinese)

Trust in clinicians

I thought like, you know, it's from hospital, obvious it's good for him. So the doctor knows better than us. (02FBangladeshi)

Being in control

It's reassuring that they kept saying that at any time we can pull out. (21F-Bangladeshi)

They explained to me that the main side effect was sleep like sleep disturbance erm... and obviously if it was too much then just stop. (04F-UK)

wholly altruistic outlook by pointing out that the results of the trial would be unlikely to benefit their own child.

A few parents (2/20 Bangladeshi, 1/10 UK, 0/12 other) based their decision to participate in the trial primarily on their trust in the research team, these families appeared not to differentiate between trial researcher and healthcare provider roles. Parents felt reassured that they could opt out of the trial at any time and, particularly if their child experienced side effects.

Beliefs about the acceptability to their child and the effects of the substance they were given-whether montelukast or placebo-were clearly important motives in maintaining or discouraging continuing participation (box 4). Four of 20 Bangladeshi parents (but no others) believed there would be no side effects, reporting that this was what the trial researcher had told them. Even parents with a well-informed understanding of the trial process said they would consider withdrawing their child if they believed the medication was not having a beneficial effect. Three (one from each ethnic group) had already decided to discontinue because their child did not like the medication or because it did not appear to be effective, or because of perceived adverse effects. Three more (2/10 UK, 1/12 other) said they would consider dropping out for similar reasons if they believed that their child had been allocated the placebo drug, or 


\section{Box 4 Effects and acceptability of medication}

They just told me there's not going to be there, there is no side effects at all. (23M-Bangladeshi)

Yes medicine he doesn't like. (22F- Bangladeshi)

I don't want there to be any side effects. Yes everything has got side effects but, it's the sleeping part and the behaviour that was another thing. I didn't want that to change. (41F-UK)

I think our first step would be if I thought he wasn't on the medicine, getting the medicine prescribed somewhere else. (05F-UK)

I mean the only reason I would come out of the trial was if I thought there was any erm... negative side effects. And we're now on our second dose of medicine and he's been totally fine. (10F-UK)

l'd go back to the hospital...and tell them the medicine you give to me maybe don't do anything. (07F-African)

The wheezing is still there and it was not going away, so I just said, I just stopped giving to him, I said I didn't think it was helping him at all. (32F-Caribbean)

if the medication seemed ineffective or harmful, indicating that subject recruitment and retention is driven strongly by the perceived likelihood of personal benefit.

\section{Information and consent}

All parents reported satisfaction with the initial trial information they had received and that all queries were answered adequately. Retention was poor however, and by the time of the interview few could recall significant detail. The decision to consent was strongly influenced by the meeting with the clinical team.

The patient information leaflet (PIL) was translated from English into Bengali, but not into other languages as Bangladeshis are by far the largest local non-English-speaking minority, with a disproportionately reduced likelihood of English literacy in comparison to other, rarer language groups (table 3). Interviewees were often evasive regarding their reading of the PIL, suggesting that this was an area of sensitivity for some respondents. Just $7(41 \%)$ of 17 Bangladeshi respondents who gave direct answers claimed to have read the leaflet (compared with 15/16 (93\%) of non-Bangladeshis); a further seven said that they had not and three said that other family members had read it for them. Box 5 shows comments made about the PIL. The length and detail of the PIL appeared to discourage reading in some (mainly Bangladeshi) respondents, placing the emphasis more firmly on personal interaction with researchers for communication of trial information.

\section{Understanding the research process}

Just over one-third of parents understood the principle of randomisation to some degree (5/20 Bangladeshi, $7 / 10$ white UK, $3 / 12$ others; see box 6 ). Bangladeshi families were least aware that a DNA sample had been taken from their child (6/20 Bangladeshi were aware, 9/10 UK, 9/12 others). Despite poor comprehension of
Table 3 Characteristics of qualitative interview participants

\begin{tabular}{|c|c|c|c|}
\hline & & White & \\
\hline & Bangladeshi & UK & Other \\
\hline Demographics & & & \\
\hline Male & 6 & 2 & 2 \\
\hline Female & 14 & 8 & 10 \\
\hline Age in years (mean (SD)) & $35(7.8)$ & $34(6.2)$ & $36(4.3)$ \\
\hline Language & & & \\
\hline First language & & & \\
\hline Bengali/Sylheti & 19 & & \\
\hline English & 1 & 10 & 4 \\
\hline French & & & 2 \\
\hline Arabic & & & 2 \\
\hline Mandarin & & & 1 \\
\hline Creole & & & 1 \\
\hline Portuguese & & & 2 \\
\hline Fluency in spoken Engli & ish* & & \\
\hline Excellent & 5 & 10 & 4 \\
\hline Good & 1 & 0 & 0 \\
\hline Fair & 5 & 0 & 5 \\
\hline Poor & 9 & 0 & 3 \\
\hline Socioeconomic & & & \\
\hline Educational attainment & & & \\
\hline Left before 16 years & 1 & & \\
\hline GCSE or equivalent & 8 & 6 & 3 \\
\hline A level or equivalent & 1 & 0 & 3 \\
\hline Graduate degree & 1 & 4 & 3 \\
\hline Postgraduate degree & 1 & & 2 \\
\hline Not answered & 8 & & 1 \\
\hline Occupation of highest e & arner in family & & \\
\hline $\begin{array}{l}\text { Higher managerial, } \\
\text { administrative and } \\
\text { professional }\end{array}$ & 1 & 2 & 2 \\
\hline Intermediate & 3 & 1 & 3 \\
\hline Routine and manual & 8 & 2 & 3 \\
\hline Student & & & 1 \\
\hline Not answered & 8 & 5 & 3 \\
\hline Total & 20 & 10 & 12 \\
\hline
\end{tabular}

personalised medicine and genetic testing concepts, most respondents viewed the genetic component of the study positively.

\section{Consulting others}

There were some differences between ethnic groups in how decisions were made to enrol their child in the trial. Some decided to consent as soon as they were approached but others sought advice from other people. Some (4/20) Bangladeshi respondents reported that they relied entirely on the medical profession to guide them, but they were the only group to express this. Some non-Bangladeshi respondents were able to call on medically qualified family members for their advice or made use of the internet and other sources of pharmaceutical information. Very few respondents $(3 / 42)$, all of white UK ethnicity, reported receiving 
negative views about the trial from family or friends. Box 7 shows relevant extracts.

\section{DISCUSSION}

\section{Summary of the main findings}

A major reason for parents agreeing to enrol their child in the trial related to their previous experiences of witnessing their child having severe wheeze attacks. This caused anxiety in many parents, regardless of ethnicity, motivating them to find an effective treatment. However, some parents found it difficult to distinguish between clinical treatment and research despite receiving information about the trial processes, including randomisation and the use of a placebo.

A second reason for enrolment was the reassurance parents received that they would retain control, regarding not only whether to remain in the study but also whether and when they gave their child the study medicine.

Third, most parents had confidence in the research team and preferred face-to-face meetings with the clinical trial researchers to reliance on written PILs. They could ask questions directly of the research team and found the prescribed and formalised information sheets too long. While none said that they had received too much information about the trial, few had read beyond the first few pages. It appears that verbal delivery of trial information was more important than study literature. Bangladeshi families demonstrated poor familiarity with essential trial concepts at interview (table 4); however, it is unclear

\section{Box 5 Comments about the patient information leaflet}

Lots of pages. Yeah, little bit I read... He explained me nicely that time. I understand what he's saying but I can't tell you now. I can't remember all of it. 01F-Bangladeshi)

Some of the first page and second page we did and then we were happy with this. We read we are so happy some of the paragraphs are very nice but it carried on and on. (15M-Bangladeshi)

That time I was very busy and I don't have time to read it, and when I had time I forgot. (25F-Bangladeshi)

I understood what she explained so I didn't really bother to read that much. (38F-Bangladeshi)

Yes of course, I read everything. Erm, I did read it, I could have read more, erm but I am one of the people who reads everything. I am used to reading complicated stuff in my work anyway. (30M-UK)

They were good explanatory, there was a lot of them but it's not the same as talking to somebody saying well look l'm worried about and then they'll they put me right. I had a better understanding and you can't ask a question on a bit of paper. (09F-UK)

It told me everything I need to know to be able to start the trial. (27F-Black UK)

Er....can't remember. Something I have to think... because it was a long time ago. (08F-Egyptian)

I read it, well both myself and my partner read it and we did find it like yeah it was absolutely fine for us. (19F Caribbean)

I read it....Just first the introduction, the introduction this research. (06M-Chinese)
Box 6 Understanding and acceptance of randomisation and DNA component

\section{Randomisation}

I totally don't know if the powder is the..er..blank one (06M-Chinese)

Well they said they were going to test so many people with this and so many people with that and then get the results and see what. 17F-Bangladeshi)

We are in a trial and we could be given a placebo or cure and that's done on a group of kids. (26M-Middle Eastern)

Yes, so I could have a treatment that is sherbet in other words. (27F-Black UK)

DNA component

They did tell me [its purpose] at the time but I really can't remember. (21F- Bangladeshi)

They told me, eh, I can't remember, sorry. (39F-African)

It's only if it didn't hurt him, it was only a swab from his mouth so no, that was fine. (04F-UK)

As long as it's not invasive (08F-Eygyptian)

I'm sure it's only used for the medical and not generally. I think the only time it would be concerning is like I said if they were going to share the information. (21F-Bangladeshi)

I haven't really thought about it. It's just part of the one part of the study that needs to be that they're looking at. I don't think there's anything sinister being done. Everyone's going to end up on a DNA database somewhere. (05F-UK)

whether this reflects poor initial understanding or poor information retention. All parents report being satisfied with the information received at recruitment; however, although similar numbers of white and Bangladeshi parents claim to have read the PIL (table 4), the information density of the PIL may have prevented complete reading (box 5), or re-reading when details had faded from memory. The disproportionate effect on Bangladeshi families may relate to the large number of non-responders to the query regarding educational attainment (table 3), where non-response may indicate a low educational level. Despite this poor information level, Bangladeshi parents were overrepresented in the parent study, reflecting a desire to participate that was likely influenced by researcher rapport (box 3 and 5) and a Bengali-speaking team member, a linguistic benefit that was lost in the

\section{Box 7 Other sources of information and reassurance}

It's from hospital obvious it's good for him. He...the doctor knows better than us. (02F-Bangladeshi)

I told him [my husband] and he said OK if you want to go you can go. (25F-Bangladeshi)

I looked at the internet I think...... where I work we've got an old copy of the BNF so I looked at that. (18M-UK)

I was pretty certain I think.. but his dad was a bit more reluctant because he's sort of thought it was a trial medicine.... and then when I explained that montelukast was already a drug... and if he has asthma and it gets progressively worse, there's a good chance it will be prescribed anyway, so.., (10F-UK) 
Table 4 Information and consent

\begin{tabular}{lcccc}
\hline & Bangladeshi & White UK & Other* & Total \\
\hline Satisfied with initial information & $20(100 \%)$ & $10(100 \%)$ & $12(100 \%)$ & $42 / 42(100 \%)$ \\
Personally read PIL & $11 / 20(55 \%)$ & $6 / 10(60 \%)$ & $4 / 12(33 \%)$ & $21 / 42(50 \%)$ \\
Had PIL read to them & $5 / 20(25 \%)$ & $4 / 10(40 \%)$ & $6 / 12(50 \%)$ & $15 / 42(36 \%)$ \\
Understanding of randomisation & $5 / 20(25 \%)$ & $7 / 10(70 \%)$ & $3 / 12(25 \%)$ & $14 / 42(33 \%)$ \\
Awareness that DNA sample taken & $6 / 20(30 \%)$ & $9 / 10(90 \%)$ & $9 / 12(75 \%)$ & $24 / 42(57 \%)$ \\
\hline PIL, patient information leaflet. & & &
\end{tabular}

translated PIL due to low literacy. Hence, parents gave informed consent, but lacked a useful written record of the details to which they had agreed.

The study found a lack of curiosity about research processes and practices among all ethnic groups. Parents were generally unconcerned regarding DNA collection, with little awareness of controversies regarding the processing of genetic material expressed by any ethnic group. Parents' primary concern in the parent study regarded potential montelukast side effects.

The findings suggest an absence of interethnic discrepancies in motivating factors for research participation. All groups were united in their anxieties regarding PSW and the need to find an effective treatment. Bangladeshi parents were distinguished by a greater respect for medical opinion and a limited grasp of spoken and written English which combined to increase their participation, but at the cost of limited understanding.

\section{Strengths and limitations of the study}

The study does not include parents who were unwilling to take part in the trial or take part in the qualitative interviews. While recruitment of Bangladeshi participants to the parent study was good, perhaps because one of the research workers was fluent in Bengali, it is clear (see table 2) that participation of these parents in the qualitative interview study was less common. This reluctance was perhaps related to concerns about coping with an interview conducted in English or with the aid of an interpreter. Future qualitative studies of this sort may be able to overcome this reluctance by employing a research worker fluent in the first language of potential respondents.

\section{Comparison with the existing literature}

This study reinforces the existing qualitative literature 2627 on recruitment to trials for children in general, and in the consent process in particular ${ }^{28}$; however, the novel aspect of this study is the contrast between different ethnic groups, especially in relation to understanding and accessible information. The difficulty some parents had in distinguishing clinical treatment from research reflects previous reports, ${ }^{8-11}$ while the finding about parental reassurance and sense of control are in line with earlier work relating to consent by proxy. ${ }^{7-11}$ Studies on lay understanding of the purpose of genetic sampling have also found a lack of concern about this. ${ }^{14} 15$

\section{Implications for the conduct of research}

We concur with the view that representative ethnic minority participation in trials is feasible if researchers take appropriate steps to facilitate this. ${ }^{5}$ It is clear that one of the stumbling blocks can be the provision of information in a 'user unfriendly' format. Modern ethics committees demand highly detailed PILs which may perversely reduce the quality of the consent decision by discouraging thorough reading and reducing assimilation of information. ${ }^{29}$ This observation is supported by the current findings. As a matter for debate, we suggest the introduction of a supplementary and abbreviated PIL with a checklist of fundamental concepts to be covered during the informed consent process (this would include the division between researcher and clinician roles). This document should be signed and a copy kept by both researcher and the study participant. The counter argument is that an abbreviated PIL would not fully inform parents; however, such a document (used alongside a detailed consent discussion) would add structure to and emphasise the importance of the discussion and also serve as a palatable aide-memoire for participants. The full PIL could be retained as a detailed reference document for parents. Approaches such as this may improve the quality and success of the consent process across the ethno-social spectrum and their investigation should be an avenue for future study.

Contributors VM carried out the interviews, analysed data and wrote the initial draft of the paper. JG, CG and CS conceived and designed the study as grant applicants. VM and CN recruited participants to the qualitative study, contributed to data interpretation and were major contributors to the final submitted draft. CS supervised VM's data collection and analysis. All authors helped in interpreting the data and critically revise successive drafts of the manuscript. All authors read and approved the final manuscript.

Funding This work was supported by the National Institute of Health Research Efficacy and Mechanism Evaluation Stream (grant number: 08-43-03).

Competing interests None.

Ethics approval South East Research Ethics Committee.

Provenance and peer review Not commissioned; externally peer reviewed.

Data sharing statement Consent for publication of raw data obtained from study participants. Original transcripts are available from the corresponding author on request.

\section{REFERENCES}

1. Hussain-Gambles $M$, Atkin K, Leese B. Why ethnic minority groups are under-represented in clinical trials: a review of the literature. Health Soc Care Community 2004;12:382-8. 
2. Mason S, Hussain-Gambles M, Leese B, et al. Representation of South Asian people in randomised clinical trials: analysis of trials' data. BMJ 2003;326:1244-5.

3. Netuveli G, Hurwitz B, Levy M, et al. Ethnic variations in UK asthma frequency, morbidity, and health service use: a systematic review and meta-analysis. Lancet 2005;365:312-17.

4. Rooney LK, Bhopal R, Halani L, et al. Promoting recruitment of minority ethnic groups into research: qualitative study exploring the views of South Asian people with asthma. J Public Health 2011;33:604-15.

5. Stirland L, Halani L, Raj B, et al. Recruitment of South Asians into asthma research: qualitative study of UK and US researchers. Prim Care Respir J 2011;20:282-90.

6. Sheikh A, Halani L, Bhopal R, et al. Facilitating the recruitment of minority ethnic people into research: qualitative case study of South Asians and asthma. Plos Med 2009;6:e1000148.

7. Shilling V, Young B. How do parents experience being asked to enter a child in a randomised controlled trial? BMC Med Ethics 2009;10:1.

8. Chappuy $\mathrm{H}$, Baruchel A, Leverger G, et al. Parental comprehension and satisfaction in informed consent in paediatric clinical trials: a retrospective study on childhood leukaemia. Arch Dis Child 2010;95:800-4.

9. De Vries MC, Houtlosser M, Wit JM, et al. Ethical issues at the interface of clinical care and research practice in pediatric oncology: a narrative review of parents' and physicians' experiences'. BMC Med Ethics 2011;12:18.

10. Joffe S. Altruistic discourse and therapeutic misconception in research informed consent. Am J Bioeth 2006;6:53-4.

11. Snowdon C, Elbourne D, Garcia J. 'It was a snap decision': parenta and professional perspectives on the speed of decisions about participation in perinatal randomised controlled trials. Soc Sci Med 2006;62:2279-90.

12. Kuehni CE, Strippoli MPF, Silverman M. Food intolerance and wheezing in young south Asian and white children: prevalence and clinical significance. J Allergy Clin Immunol 2006;118:528-30.

13. Reilly P. Public concern about genetics. Ann Rev Genomics H Gen 2000;1:485-506.

14. Streicher SA, Sanderson SC, Jabs EW, et al. Reasons for participating and genetic information needs among racially and ethnically diverse biobank participants: a focus group study. J Community Genet 2011;2:153-63.
15. Murphy J, Scott J, Kaufman D, et al. Public perceptions of informed consent for biobanking. Am J Public Health 2009;99:2128-34.

16. Patton MQ. Qualitative evaluation and research methods. USA Sage Publications, 1990.

17. Ferguson PR. Patients' perceptions of information provided in clinical trials. J Med Ethics 2002;28:45-8.

18. Woodgate RL, Yanofsky RA. Parents' experiences in decision making with childhood cancer clinical trials. Cancer Nurs 2010;33:11.

19. NVivo qualitative data analysis software. QSR International Pty Ltd. Version 10, 2012.

20. Glaser BG. Basics of grounded theory analysis. Mill Valley, CA Sociology Press, 1992

21. Pope C, Ziebland S, Mays N. Analysing qualitative data. Br Med J 2000;320:114-16.

22. Richards L, Richards T. The transformation of qualitative method: computational paradigms and research processes. In: Fielding $\mathrm{N}$ Lee $\mathrm{R}$, eds. Using computers in qualitative research. London: Sage, 1993:38-53.

23. www.biomedcentral.com/ifora/rats (accessed 2 Dec 2012).

24. Huberman M, Miles M, eds. The qualitative researcher's companion. Thousand Oaks: Sage, 2002.

25. Data on local population is for 2006-7. http://thisborough towerhamlets.gov.uk/metadata.asp?DBElement Type $=$ Indicator\&DBElementID=4533\&GeographyTypeID=30\& DatelD=2006-06-30\&Period=Year (accessed Aug 2012).

26. Shilling V, Williamson $\mathrm{PR}$, Hickey $\mathrm{H}$, et al. Processes in recruitment to randomised controlled trials of medicines for children (RECRUIT): a qualitative study. Health Technol Assess 2011;

15:1-116.

27. Shilling V, Williamson PR, Hickey $\mathrm{H}$, et al. Communication about children's clinical trials as observed and experienced: qualitative study of parents and practitioners. PLOS ONE 2011;6: e21604.

28. Beardsley E, Jefford M, Mileshkin L. Longer consent forms for clinical trials compromise patient understanding: so why are they lengthening? J Clin Oncol 2007;25:e13-14.

29. Shukla AN, Daly MK, Legutko P. Informed consent for cataract surgery: patient understanding of verbal, written, and videotaped information. J Cataract Refract Surg 2012;38:80-4. 